\title{
Transient Thermal Modelling of Substation Connectors by Means of Dimensionality Reduction
}

\author{
C. Abomailek ${ }^{1}$, F. Capelli ${ }^{1}$, J.-R. Riba ${ }^{1 *}$, and P. Casals-Torrens ${ }^{1}$ \\ 1 Department of Electrical Engineering, Universitat Politècnica de Catalunya, 08222 Terrassa, Spain \\ * Corresponding author: riba@ee.upc.edu; Tel.:+34-93-739-83-65
}

\begin{abstract}
This paper proposes a simple, fast and accurate simulation approach based on one-dimensional reduction and the application of the finite difference method (FDM) to determine the temperatures rise in substation connectors. The method discretizes the studied three-dimensional geometry in a finite number of one-dimensional elements or regions in which the energy rate balance is calculated. Although a onedimensional reduction is applied, to ensure the accuracy of the proposed transient method, it takes into account the three-dimensional geometry of the analyzed system to determine for all analyzed elements and at each time step different parameters such as the incremental resistance of each element or the convective coefficient. The proposed approach allows fulfilling both accuracy and low computational burden criteria, providing similar accuracy than the three-dimensional finite element method but with much lower computational requirements. Experimental results conducted in a high-current laboratory validate the accuracy and effectiveness of the proposed method and its usefulness to design substation connectors and other power devices and components with an optimal thermal behavior.
\end{abstract}

Keywords - Thermal model, finite difference, simulation, connector, heat transfer.

\section{NOMENCLATURE}

$i=1,2, \ldots, I \quad$ Node index identifying the position along the $x$ axis

$j=1,2, \ldots, J \quad$ Time step index

cd Abbreviation of conductor

conn Abbreviation of connector

$\Delta x \quad$ Spatial step [m]

$\Delta t \quad$ Time step [s]

$T \quad$ Temperature $[\mathrm{K}]$

$T i^{j} \quad$ Temperature $[\mathrm{K}]$ at node $i \cdot \Delta x$ and time instant $j \cdot \Delta t$

$T_{o} \quad$ Reference temperature, $293.15 \mathrm{~K}$

$T_{c d, \infty} \quad$ Conductor temperature far from the connector [K]

$T_{\text {air }, \infty} \quad$ Air temperature far from the conductor $[\mathrm{K}]$

$T_{\text {film }} \quad$ Film temperature $[\mathrm{K}]$

$H_{\text {sea }} \quad$ Conductor elevation above sea level [m]

$\dot{Q} \quad$ Rate of energy with respect to time [W]

$D_{c d} \quad$ Outer diameter of the conductor [m]

$C_{p} \quad$ Specific heat $[\mathrm{J} /(\mathrm{kg} \cdot \mathrm{K})]$

$k \quad$ Coefficient of thermal conductivity $[\mathrm{W} /(\mathrm{m} \cdot \mathrm{K})]$

$\rho \quad$ Mass density $\left[\mathrm{kg} / \mathrm{m}^{3}\right]$

$\rho_{e} \quad$ Electrical resistivity $[\Omega \cdot \mathrm{m}]$

$\alpha_{e} \quad$ Temperature coefficient of the resistivity $[1 / \mathrm{K}]$

$R \quad$ Electrical resistance $[\Omega]$

$r \quad$ Electrical resistance per unit length $[\Omega / \mathrm{m}]$

$I_{e} \quad$ Electric current $[\mathrm{A}]$

$S \quad$ Cross sectional area perpendicular to the electric current $\left[\mathrm{m}^{2}\right]$

$P \quad$ Convective/radiative heat transfer perimeter $[\mathrm{m}]$

$P \cdot \Delta x \quad$ Convective/radiative heat transfer incremental area $\left[\mathrm{m}^{2}\right]$ 


$\begin{array}{ll}h & \text { Convective heat transfer coefficient }\left[\mathrm{W} /\left(\mathrm{m}^{2} \cdot \mathrm{K}\right)\right] \\ \varepsilon & \text { Emissivity } \\ \sigma & \text { Stefan-Boltzmann constant }\left[\mathrm{W} /\left(\mathrm{m}^{2} \cdot \mathrm{K}^{4}\right)\right] \\ \mu & \text { Dynamic viscosity of air }[\mathrm{Pa} \cdot \mathrm{s}] \\ \beta & \text { Thermal expansion coefficient of air }[1 / \mathrm{K}] \\ g & \text { Gravity of Earth }\left[\mathrm{m} / \mathrm{s}^{2}\right] \\ \theta & \text { Angular coordinate }\left[{ }^{\circ}\right] \\ L_{c} & \text { Characteristic length }[\mathrm{m}] \\ N u & \text { Nusselt dimensionless number } \\ P r & \text { Prandtl dimensionless number } \\ G r & \text { Grashof dimensionless number }\end{array}$

\section{INTRODUCTION}

During the last years, the finite element method (FEM) has been widely applied to design electrical devices. Two- and three-dimensional (2D and 3D) multiphysics FEM simulations are recognized as a realistic means to predict the electromagnetic and thermal behavior of diverse type of electrical devices. Different authors have struggled to develop coupled electromagnetic-thermal 2D- and 3D-FEM formulations to predict the thermal behavior of diverse electrical components such as conductors, bus bars, cables, connectors or semiconductors among others [1-9]. Despite significant improvements in computer performance, 3D-FEM simulations are still time-consuming and memory-intensive due to the heavy computational resources involved to provide the required resolution for complex 3D multiphysic problems [10]. It can cause serious difficulties, particularly when applying recursive simulations during the design optimization stage [11]. The use of 3D-FEM simulation tools often requires the use of costly licenses and the implication of specialized engineers to carry out tedious and time-consuming tasks associated to the preparation of 3D geometries, generation of the 3D mesh, or settling of boundary conditions among others. Therefore the development of accurate fast models [12] which can be based on model reduction techniques [13] and are highly appealing to overcome the abovementioned drawbacks.

Different approaches have been applied to reduce the computational burden in complex 3D problems. For example in [14] a co-simulation strategy combining 1D finite difference and 3D finite volume codes are applied. In [15] a1D analytical model for simulating the response of piezoelectric transformers was compared against 3D-FEM simulations. In [16] a 1D finite difference approach to model mass conservation in ducts of an internal combustion engine was studied. Cerfontaine et al. [17] proposed a 1D-finite element formulation to model the grouting and field temperatures of borehole heat exchangers.

This paper proposes a one-dimensional fast method based on nodal equations and finite differences formulation to accurately predict the temperature evolution in substation connectors during the standard temperature rise test. This is a multiphysics electromagnetic-thermal problem since the main heat source is the Joule loss due to the electric current whose time-profile is known, although there is a minor contribution due to the induced eddy currents. The proposed method discretizes the analyzed domain in finite one-dimensional regions in which the energy rate balance due to the flow of heat is calculated. To accurately predict the temperature profile along the connector and the surrounding conductors, the proposed transient model takes into account the three-dimensional geometry of the analyzed system to determine for each discretized element and at each time step different parameters such as the incremental electrical resistance or the convective coefficient. It is worth noting that the proposed approach can also be applied to simulate the temperature rise of other power devices.

To evaluate the accuracy of the proposed system, two substation connectors are evaluated and the standardized temperature rise test according to the ANSI/NEMA CC1-2009 standard [18] is simulated and 
checked against experimental tests. According to this standard, the connector passes the test if its temperature is below the temperature of the conductors at with which the connector is associated. This test is very useful since it allows evaluating the thermal behavior of the substation connectors under both transitory and stationary conditions. Temperature rise tests are expensive since they last for long time, and consume large amounts of electrical power. As a result, to obtain designs with optimal thermal performance [19], substation connectors' manufacturers require fast, easy-to-use and accurate simulation tools to anticipate the results of the mandatory standard temperature rise tests.

The finite difference method (FDM) is a recognized tool to approximate the solutions of systems governed by differential equations by means of finite differences calculated at the grid points of a discretized geometry. The FDM method has been widely applied in the technical bibliography, for example to model the heat transfer in solar cells by applying the conservation principle [20], calculate the natural convection heat transfer in a cavity filled with a nanofluid [21,22], determine the temperature rise of a surgical drilling machine [23], model the transient thermal performance of machining processes [24], predict the temperature distribution of ball-screw mechanical systems [25] or to perform vibrational analysis in elastic media [26].

Most of the works are based on two- or three-dimensional FDM approaches. In this paper it is shown that by using a one-dimensional FDM reduction by considering the whole three-dimensional geometry in calculating key parameters for the energy conservation laws it is possible to obtain very accurate results, similar to those attained with 3D-FEM, which is the current way to solve this kind of problems [27], but with much less computational burden. As a consequence, the method here proposed can be very useful to optimize in an economical and fast manner the design of different power devices including substation connectors, power conductors, busbars or fittings used in power lines among others to ensure an improved thermal behavior.

\section{The Model Bases On Nodal Equations And Finite Difference Formulation}

\subsection{Problem discretization}

The temperature of the connector is directly related to the temperature of the reference conductors at which it is connected. Due to the longitudinal geometry and heat conduction of the considered problem, the thermal analysis can be reduced to a one-dimensional problem by formulating suitable assumptions. To this end the whole domain is divided into several discrete elements called nodes, along the axial and main dimension of the geometry, as shown in Fig. 1. The axial dimension is selected to solve the heat transfer problem because it is the dimension where almost all heat conduction occurs. It is assumed that the temperature of the central point of the any node is the average temperature of this node. This assumption is accurate since connectors are made of good conductor materials such as copper and aluminum and because a small enough spatial step $\Delta x$ is selected.

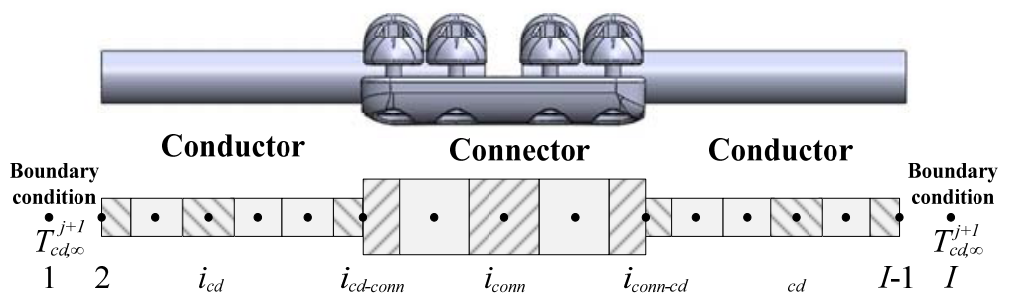

Fig. 1. Conductor-connector discretization.

FDM is based on replacing the partial derivatives by approximations using Taylor expansions near the discrete points of the geometry under study. The temperature calculation in each node is based on the temperature of the two adjacent nodes, that is the left-side and right-side nodes. Since three nodes are 
involved in each calculation step, a three-diagonal matrix system of equations can be generated. As a consequence, the TDMA (tri-diagonal matrix algorithm) algorithm [28] is well-suited to solve this problem since it allows calculating the temperatures in all nodes simultaneously. A tridiagonal matrix corresponds to a system of equations given by,

$$
a_{i}^{j} \cdot T_{i-1}^{j+1}+b_{i}^{j} \cdot T_{i}^{j+1}+c_{i}^{j} \cdot T_{i+1}^{j+1}=d_{i}^{j}
$$

$T_{i}^{j}=(i \cdot \Delta x, j \cdot \Delta t)$ being the temperature in the $\underline{i}$-th node $(i=1,2, \ldots, I)$ at the $j$-th time step, $\mathrm{t}$ and $a_{i}^{j}, b_{i}^{j}, c_{i}^{j}$ and $d_{i}^{j}$ the constant coefficients in equation $i$-th. It is worth noting that superscript $j$ refers to time steps whereas subscript $i$ is used for spatial steps. The system of equation in all nodes can be represented in matrix form as,

$$
\left[\begin{array}{ccccc}
b_{1}^{j} & c_{1}^{j} & & & a_{1}^{j} \\
a_{2}^{j} & b_{2}^{j} & c_{2}^{j} & & \\
& a_{3}^{j} & b_{3}^{j} & \cdot & \\
& & \cdot & \cdot & c_{I-1}^{j} \\
c_{I}^{j} & & & a_{I}^{j} & b_{I}^{j}
\end{array}\right]\left[\begin{array}{c}
T_{1}^{j+1} \\
T_{2}^{j+1} \\
\cdot \\
\cdot \\
T_{I}^{j+1}
\end{array}\right]=\left[\begin{array}{c}
d_{1}^{j} \\
d_{2}^{j} \\
\cdot \\
\cdot \\
d_{I}^{j}
\end{array}\right]
$$

where $a_{1}^{j}=0$ and $c_{I}^{j}=0$. Therefore once all coefficients $a_{i}^{j}, b_{i}^{j}, c_{i}^{j}$ and $d_{i}^{j}(i=1 \ldots I)$ are known, the temperature vector of unknown variables $\left[T_{1}^{j+1}, T_{2}^{j+1}, \ldots, T_{I}^{j+1}\right]$ can be solved by applying the TDMA algorithm.

It is noted that $a_{i}^{j}$ is the coefficient agglutinating all the terms multiplying $T_{i-1}^{j+1}, b_{i}^{j}$ is the coefficient that agglutinates all the terms multiplying $T_{i}^{j+1}, c_{i}^{j}$ is the coefficient agglutinating all the terms multiplying $T_{i+1}^{j+1}$, whereas $d_{i}^{j}$ is the coefficient that agglutinates all the independent terms in (1).

\subsection{Energy rate balance}

To determine the actual temperature in all nodes of the analyzed domain, the energy rate balance equation must be applied to each node,

$\dot{Q}_{\text {change }}=\left(\dot{Q}_{\text {input }}+\dot{Q}_{\text {generation }}\right)-\left(\dot{Q}_{\text {output }}+\dot{Q}_{\text {consumption }}\right)$

$\dot{Q}[\mathrm{~W}]$ being the rate of energy with respect to time. Taking into account the differential element shown in Fig. 2, (3) can be rewritten as,

$$
\dot{Q}_{\text {change }}=\left(\dot{Q}_{\text {conduction_left }}+\dot{Q}_{\text {generation }}\right)-\left(\dot{Q}_{\text {convection }}+\dot{Q}_{\text {radiation }}+\dot{Q}_{\text {conduction_right }}\right)
$$

$\dot{Q}_{\text {change }}[\mathrm{W}]$ being the rate of energy change within the considered element, $\dot{Q}_{\text {conduction_left }}$ the rate of energy inputting the left side of the considered element, $\dot{Q}_{\text {generation }}$ the rate of energy generated and $\dot{Q}_{\text {conduction_right }}$ the rate of energy outputting the right side of considered element, $\dot{Q}_{\text {convection }}$ the rate of convective cooling through the outer surface and $\dot{Q}_{\text {radiation }}$ the rate of radiative cooling.

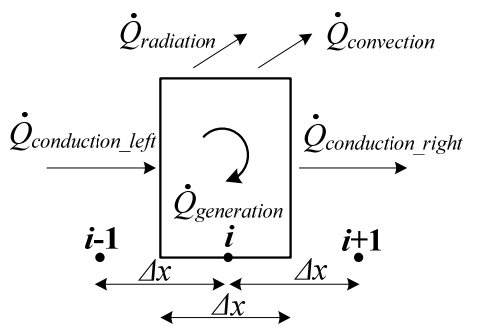

Fig. 2. Components of the rate of energy in a general element of the considered domain.

The terms in (4) are calculated as follows, 


$$
\left\{\begin{array}{l}
\dot{Q}_{\text {change }}=\rho \cdot S \cdot C p \cdot \frac{T_{i}{ }^{j+1}-T_{i}{ }^{j}}{\Delta t} \cdot \Delta x \\
\dot{Q}_{\text {generation }}=I_{e}^{2} \cdot \frac{\rho_{e}\left(T_{i}{ }^{j}\right)}{S} \cdot \Delta x \\
\dot{Q}_{\text {conduction_left }}=-k\left(T_{i}{ }^{j}\right) \cdot \frac{T_{i}{ }^{j+1}-T_{i-1}{ }^{j+1}}{\Delta x} \cdot S \\
\dot{Q}_{\text {convection }}=h\left(T_{i}{ }^{j}\right) \cdot P \cdot\left(T_{i}{ }^{j+1}-T_{\text {air }}\right) \cdot \Delta x \\
\dot{Q}_{\text {radiation }}=\varepsilon \cdot \sigma \cdot P\left[\left(T_{i}{ }^{j+1}\right)^{4}-T_{\text {air }}{ }^{4}\right] \cdot \Delta x \\
\dot{Q}_{\text {conduction_right }}=-k\left(T_{i}{ }^{j}\right) \cdot \frac{T_{i+1}{ }^{j+1}-T_{i}{ }^{j+1}}{\Delta x} \cdot S
\end{array}\right.
$$

$\Delta t$ and $\Delta x$ being, respectively, the discretized time and spatial steps taken in the simulations. Note that $S$ is the cross-sectional area perpendicular to the conduction heat flux and $P \cdot \Delta x$ is the radiation and convection area in the considered element, $P$ being the outer perimeter. It should be pointed out that parameters $S, h$ and $P$ depend on the 3D geometry of the problem, so they are calculated in each node by considering the 3D information.

The finite-difference method (FDM) is a numerical discretization algorithm that allows approximating the solutions of differential equations by applying difference equations. It is worth noting that to ensure the numerical stability, implicit FDM algorithms are preferred [29]. As a consequence, an implicit FDM algorithm is proposed, which solves (1) using backward differences.

It is noted that the values of physical parameters involved in the calculation of the thermal behavior of connectors such as $k, h$, or $\rho_{e}$ are evaluated at the $j$-th time step since the TDMA algorithm is an implicit calculation method that calculates future temperature values in this case under analysis, from the present known values of the physical parameters and temperatures. Therefore, by considering a small enough time step, it is assumed that the change of physical parameters values between two consecutive time steps is almost negligible. Implicit methods often provide more stable solutions than explicit methods. Although the later ones are faster, implicit methods provide reliable and fast enough solutions when dealing with onedimension problems.

Equation (3) is applied to all nodes $i=1,2, \ldots, I$ over the discretized time simulation interval $t=[0, \Delta t$, $2 \cdot \Delta t, \ldots, j \cdot \Delta t, \ldots, J \cdot \Delta t]$ with $j=1,2, \ldots, J$.

It should be noted that several assumptions have been made. The electrical resistivity $\rho_{e}$ of the material has been considered isotropic for both the connector and the conductor. Cooling effects are considered by means of natural convection and radiation. There are two main ways to calculate the convective cooling effects. The first and more accurate one is to simulate the behavior of the fluid surrounding the connector. Since this approach is very computationally intensive and thus time-consuming it is not the most suitable option when designing a fast simulation tool. So, the empirical correlation of Qureshi and Ahmad [30] for convective cooling in horizontal cylinders was applied since it provides accurate enough results. Similar approaches are found in [31,32].

Radiative cooling is also considered, since it is assumed that both conductor and connector are radiating towards a black body at the ambient temperature. This is an accurate approach for indoor tests. Other sources of heat such as incident solar radiation are not considered since the tests are conducted indoors.

\subsection{Boundary and initial conditions}

Assuming the initial temperature of the conductor is the same than that of the surrounding air, the initial conditions are defined as,

$$
T_{i}^{1}=T_{a i r, \infty} \quad i=1, \ldots, I
$$


Assuming the geometry discretization shown in Fig. 1, the following boundary conditions are imposed,

$$
\left\{\begin{array}{l}
T_{1}^{j}=T_{c d, \infty}^{j} \\
T_{I}^{j}=T_{c d, \infty}^{j}
\end{array}\right.
$$

The temperature $T_{c d, \infty}^{j}$ of the conductor very far apart from the connector (points 1 and $I$ in Fig. 1) are calculated at each time step $j$ by applying the simplified transient calculation method proposed in the IEEE738 standard [33]. It is based on solving the first order differential equation corresponding to the heat balance as a difference equation,

$$
T_{c d, \infty}^{j}=T_{c d, \infty}^{j-1}+\Delta T
$$

where

$\Delta T=\frac{\Delta t}{m \cdot C p} \cdot\left\{I_{e}^{2} \cdot r\left(T_{c d, \infty}^{j-1}\right)-\varepsilon_{c d} \cdot \sigma \cdot \pi \cdot D_{c d} \cdot\left[\left(T_{c d, \infty}^{j-1}\right)^{4}-T_{a i r}^{4}\right]-h_{c d}\left(T_{c d, \infty}^{j-1}\right) \cdot \pi \cdot D_{c d} \cdot\left(T_{c d, \infty}^{j-1}-T_{a i r}\right)\right\}$

$h\left[\mathrm{~W} /\left(\mathrm{m}^{2} \cdot \mathrm{K}\right)\right]$ being the convection coefficient, $\varepsilon$ the dimensionless emissivity coefficient, $\sigma\left[\mathrm{W} /\left(\mathrm{m}^{2} \cdot \mathrm{K}^{4}\right)\right]$ the Stefan-Boltzmann constant, $C p[\mathrm{~J} /(\mathrm{kg} \cdot \mathrm{K})]$ the specific heat of the conductor material, $D_{c d}[\mathrm{~m}]$ the outer diameter of the conductor, $T_{c d}[\mathrm{~K}]$ its surface temperature, $r(T)[\Omega / \mathrm{m}]$ the electrical resistance of the conductor per unit length and $I[\mathrm{~A}]$ the electric current. Note that (9) assumes natural convection although it can be modified to deal with forced convection.

The convective coefficient $h_{c d}$ is calculated as,

$$
h_{c d}\left(T_{c d, \infty}^{j-1}\right)=\frac{3.645}{\pi} \cdot \rho_{a i r}\left(T_{c d, \infty}^{j-1}\right)^{0.5} \cdot D_{c d}^{-0.25} \cdot\left(T_{c d, \infty}^{j-1}-T_{a i r}\right)^{0.25}
$$

fair $\left[\mathrm{kg} / \mathrm{m}^{3}\right]$ being the air density, which can be calculated as,

$\rho_{\text {air }}\left(T_{c d, \infty}^{j-1}\right)=\frac{1.293-152.5 \cdot 10^{-6} \cdot H_{\text {sea }}+6.379 \cdot 10^{-9} \cdot H_{\text {sea }}^{2}}{1+0.00367 \cdot\left(T_{\text {fitm }}^{j-1}-273.15\right)}$

$H_{\text {sea }}[\mathrm{m}]$ being the elevation of the conductor above sea level and $T_{\text {film }}$ is defined as,

$T^{j-1}=\left(T_{a i r}+T_{c d, \infty}^{j-1}\right) / 2$

\subsection{Calculation of the resistance of the connector}

Substation connectors have complex shapes. As explained, the calculation process discretizes the geometry in small elements, each one having its own incremental resistance $\Delta R_{i}^{j+1}$ and convective coefficient $h_{\text {conn }}\left(T_{i}^{j-1}\right)$ must be adapted to the specific shape and temperature of the incremental element.

To calculate the resistance of the connector a three-step procedure is applied. First the connector is divided in several slices of the same thickness, whose parallel faces are perpendicular to the direction of the electric current. By increasing the number of faces the accuracy also increases. Next, a convex-hull algorithm is applied to determine the envelope and the inner area in this envelope. Finally, the resistance of the connector is obtained by adding the incremental resistances of all slices as,

$$
R_{\text {conn }}\left(T^{j-1}\right)=\sum_{k=1}^{\text {num }_{\text {slices }}} \Delta R_{\text {slice }, k}\left(T^{j-1}\right)=\sum_{k=1}^{n u m \text { slices }} \rho_{e},_{\text {conn }}\left(T^{j-1}\right) \cdot \frac{\Delta x}{S_{\text {slice }, k}}
$$

where,

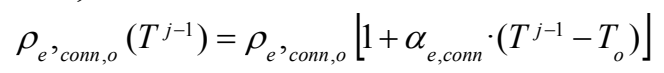

$\rho_{e, \text { conn }}[\Omega \cdot \mathrm{m}]$ being the electrical resistivity of the connector material, $\alpha_{e, \text { conn }}[1 / \mathrm{K}]$ the temperature coefficient of the resistivity and $T_{o}$ the reference temperature. Fig. 3 shows the slices obtained from the 3D$\mathrm{CAD}$ file of the analyzed connectors and the results from the convex-hull algorithm. 


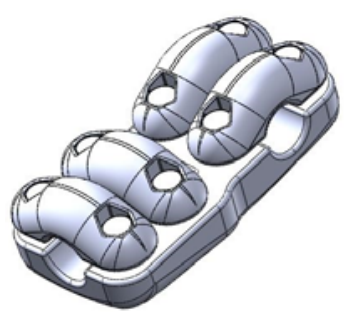

a)
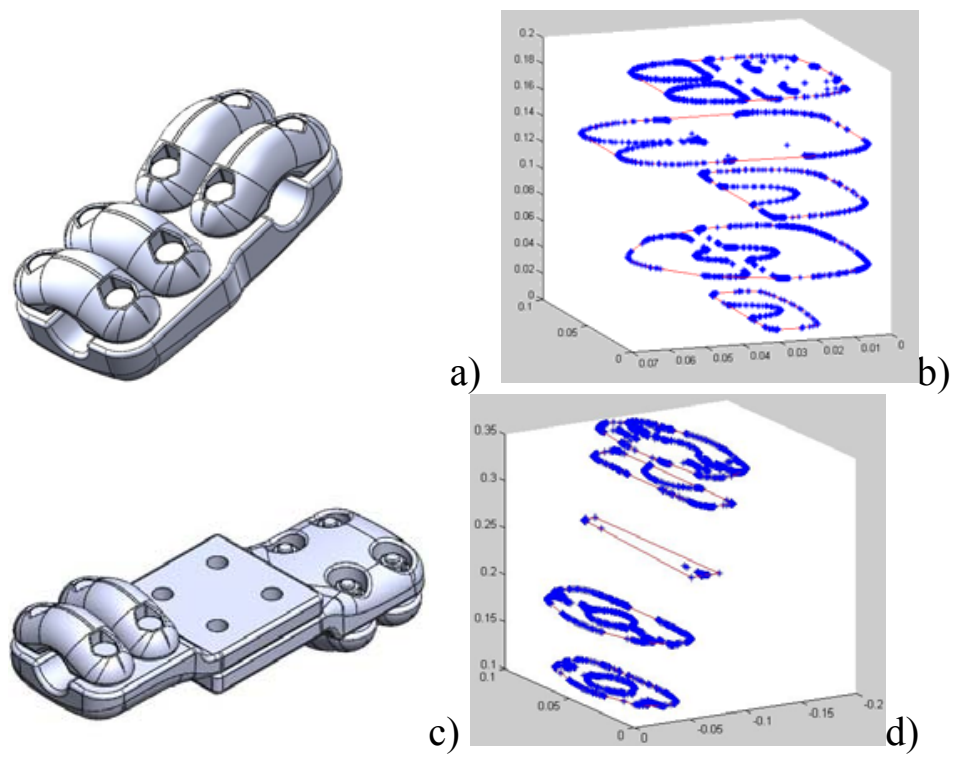

Fig. 3. a) CAD of the analyzed the T-type S285ZTLS connector. b) Convex-hull envelopes of the T-type S285ZTLS connector after dividing the domain in different slices. c) CAD of two S285ZA4P23LS terminal connectors as usually joined. d) Convex-hull envelopes of the S285ZA4P23LS terminal connectors after dividing the domain in different slices.

\subsection{Convective coefficient of the connector}

In this section natural convection is assumed since it is the most restrictive case regarding cooling performance and most tests are done indoors. The convective coefficient $h$ is a key parameter to accurately compute the energy rate balance in the nodes considered in the discretized model, which depends on geometry, fluid properties and surface and air temperatures. The convective coefficient $h_{t r i}$ in each triangle of the discretized outer surface of the connector is computed from the dimensionless Nusselt number $N u$, the thermal conductivity of air $k[\mathrm{~W} /(\mathrm{m} \cdot \mathrm{K})]$ and the characteristic length $L_{c}[\mathrm{~m}]$,

$$
h_{t r i}=k \cdot N u / L_{c}
$$

The characteristic length $L_{c}$ is calculated as the cubic root of the connector's volume. The Nusselt number for natural convection in horizontal cylinders from Qureshi and Ahmad [34,35] has been used to determine the convective coefficient $h$. Values used in the simulations were interpolated from Table I, which shows the value of the Nusselt number as a function of the angular coordinate $\theta$ and the Rayleigh number.

TABLE I

NuSSELT NUMBER As A FUNCTION OF ANGLE AND RAYLEIGH NUMBER For HORIZONTAL CYLINDERS

\begin{tabular}{|c|c|c|c|c|c|c|c|}
\hline$R a$ & $\begin{array}{l}N u(\theta) \\
\theta=0^{\circ}\end{array}$ & $30^{\circ}$ & $60^{\circ}$ & $90^{\circ}$ & $120^{\circ}$ & $150^{\circ}$ & $180^{\circ}$ \\
\hline $10^{-2}$ & 0.48 & 0.47 & 0.46 & 0.46 & 0.43 & 0.45 & 0.45 \\
\hline $10^{-1}$ & 0.70 & 0.70 & 0.69 & 0.68 & 0.68 & 0.67 & 0.67 \\
\hline $10^{0}$ & 0.93 & 0.92 & 0.90 & 0.86 & 0.82 & 0.79 & 0.78 \\
\hline $10^{1}$ & 1.34 & 1.32 & 1.28 & 1.20 & 1.11 & 1.03 & 1.00 \\
\hline $10^{2}$ & 2.06 & 2.05 & 1.99 & 1.88 & 1.70 & 1.48 & 1.38 \\
\hline $10^{3}$ & 3.03 & 3.02 & 2.96 & 2.83 & 2.59 & 2.17 & 1.88 \\
\hline $10^{4}$ & 4.50 & 4.7 & 4.39 & 4.23 & 3.94 & 3.30 & 2.57 \\
\hline $10^{5}$ & 6.76 & 6.72 & 6,58 & 6.35 & 5.95 & 5.10 & 3.50 \\
\hline $10^{6}$ & 10.23 & 10.16 & 9.95 & 9.59 & 9.04 & 7.84 & 4.85 \\
\hline $10^{7}$ & 15.50 & 15.39 & 15.08 & 14.57 & 13.77 & 12.07 & 6.88 \\
\hline
\end{tabular}


The Nusselt number was recalculated at each time step since it depends upon temperature, and evaluated in each triangle of the outer connector's surface of the 3D-CAD geometry. From the Nusselt number, the convective coefficient $h_{t r i}$ of each triangle is calculated by means of (15) and finally the overall heat transfer coefficient $h$ for the connector is obtained through the weighted average of the individual $h_{\text {tri }}$ of each triangle by using the area of each triangle as weighting factor.

To obtain the dimensionless Rayleigh number, it is first necessary to obtain the dimensionless Prandtl and Grashof numbers,

$$
R a=\operatorname{Pr} \cdot G r
$$

The Prandtl number is calculated as,

$$
\operatorname{Pr}=\frac{\mu \cdot C p}{k}
$$

$\mu[\mathrm{Pa} \cdot \mathrm{s}]$ being the dynamic viscosity of air and $C_{p}[\mathrm{~J} /(\mathrm{kg} \cdot \mathrm{K})]$ the specific heat of air.

The Grashof number is calculated as,

$$
G r=\frac{g \cdot \beta \cdot \rho^{2} \cdot\left(T_{s}-T_{a i r, \infty}\right) \cdot L_{c}^{3}}{\mu^{2}}
$$

$g\left[\mathrm{~m} / \mathrm{s}^{2}\right]$ being the gravity of Earth, $\beta[1 / \mathrm{K}]$ the thermal expansion coefficient of air, $\rho[\mathrm{kg} / \mathrm{m} 3]$ the air volumetric mass density, $T_{a i r, \infty}[\mathrm{K}]$ the air temperature far from the object's surface and $T_{s}[\mathrm{~K}]$ the surface temperature. Air properties $\rho, \mu, \quad \beta$ and $k$ depend upon film temperature, so they are recalculated at every time step from tabulated valued found in [36]. The film temperature $T_{\text {film }}$ is defined as,

$$
T_{\text {film }}=\left(T_{\text {air }, \infty}+T_{s}\right) / 2
$$

\subsection{Thermal FDM based on nodal equations}

A numerically stable implicit one-dimensional model based on the finite difference method to calculate the temperature on each discrete node of the studied volume is proposed. As explained, the TDMA method [28] allows solving this problem since the temperature of any node depends upon the temperatures of the two adjacent nodes. By analyzing the $I$ nodes (see Fig. 1) of the considered geometry a $I x I$ matrix is obtained from which the temperatures in all $I$ nodes are calculated by means of the TDMA algorithm. Four types of nodes must be considered to accurately predict the temperature distribution along the considered domain as detailed below.

\subsubsection{First node and last nodes}

A first node is considered to only set the boundary condition, that is, $T_{1}^{j+1}=T_{c d, \infty}^{j+1}$, which results in the coefficients in (1),

$$
a_{1}=0, b_{1}=1, c_{1}=0, d_{1}=T_{c d, \infty}^{j+1}
$$

$T_{c d, \infty}^{j+\infty}$ is the initial condition in the conductor, very far from the connector, which is calculated according to method found in the IEEE-738 standard and detailed in Section II-C.

Similarly for the last node also sets the boundary condition at the other side of the conductor, $T_{I}^{j+1}=T_{c d, \infty}^{j+1}$.

The constant coefficients of this node result in,

$$
a_{I}=0, b_{I}=1, c_{I}=0, d_{I}=T_{c d, \infty}^{j+1}
$$

\subsubsection{Second and penultimate node}

The second node represents the interface linking the conductor very far from the connector initial condition $T_{c d, \infty}^{j+1}$ and the regular conductor. The energy rate balance in (4) is applied to node 2 as shown in Fig. 4, resulting in (22), 


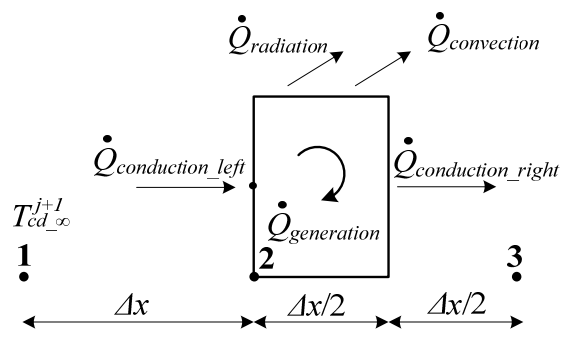

Fig. 4. Energy rate balance in node 2.

$\left\{\begin{array}{l}\dot{Q}_{\text {change }}=\rho_{c d} \cdot S_{c d} \cdot C p_{c d} \cdot \frac{T_{2}^{j+1}-T_{2}^{j}}{\Delta t} \cdot \frac{\Delta x_{c d}}{2} \\ \dot{Q}_{\text {generation }}=I_{e}^{2} \cdot \frac{\rho_{e, c d}\left(T_{2}^{j}\right)}{S_{c d}} \cdot \frac{\Delta x_{c d}}{2} \\ \dot{Q}_{\text {conduction_left }}=-k_{c d}\left(T_{2}^{j}\right) \cdot \frac{T_{2}^{j+1}-T_{c d, \infty}{ }^{j+1}}{\Delta x_{c d}} \cdot S_{c d} \\ \dot{Q}_{\text {convection }}=h_{c d}\left(T_{2}^{j}\right) \cdot P_{c d} \cdot\left(T_{2}^{j+1}-T_{a i r}\right) \cdot \frac{\Delta x_{c d}}{2} \\ \dot{Q}_{\text {radiation }}=\varepsilon_{c d} \cdot \sigma \cdot P_{c d} \cdot\left[\left(T_{2}^{j}\right)^{4}-T_{a i r}{ }^{4}\right] \cdot \frac{\Delta x_{c d}}{2} \\ \dot{Q}_{\text {conduction } r \text { right }}=-k_{c d}\left(T_{2}^{j}\right) \cdot \frac{T_{3}^{j+1}-T_{2}^{j+1}}{\Delta x_{c d}} \cdot S_{c d}\end{array}\right.$

Coefficients $a_{2}^{j}, b_{2}^{j}$ and $c_{2}^{j}$ in (1) are calculated by grouping terms $T_{1}^{j+1}=T_{c d, \infty}^{j+1}, T_{2}^{j+1}$ and $T_{3}^{j+1}$, respectively, whereas coefficient $d_{2}^{j}$ includes the remaining terms,

$$
\left\{\begin{aligned}
a_{2}^{j}=c_{2}^{j}=-k_{c d}\left(T_{2}^{j}\right) \cdot \frac{S_{c d}}{\Delta x_{c d}} \\
b_{2}^{j}=\rho_{c d} \cdot S_{c d} \cdot C p_{c d} \cdot \frac{\Delta x_{c d}}{2 \cdot \Delta t}+2 \cdot k_{c d}\left(T_{2}^{j}\right) \cdot \frac{S_{c d}}{\Delta x_{c d}}+h_{c d}\left(T_{2}^{j}\right) \cdot P_{c d} \cdot \frac{\Delta x_{c d}}{2} \\
d^{j}=\rho_{c d} \cdot S_{c d} \cdot C p_{c d} \cdot \frac{\Delta x_{c d}}{2 \cdot \Delta t} \cdot T_{2}^{j}+I_{e}^{2} \cdot \frac{\rho_{e, c d}\left(T_{2}^{j}\right)}{S_{c d}} \cdot \frac{\Delta x_{c d}}{2}+ \\
\quad+h_{c d}\left(T_{2}^{j}\right) \cdot P_{c d} \cdot T_{a i r} \cdot \frac{\Delta x_{c d}}{2}-\varepsilon_{c d} \cdot \sigma \cdot P_{c d} \cdot\left[\left(T_{2}^{j}\right)^{4}-T_{a i r}{ }^{4}\right] \cdot \frac{\Delta x_{c d}}{2}
\end{aligned}\right.
$$

It is worth noting that TDMA does not accept temperatures raised to the fourth power, therefore the radiation term applies $\left(T_{2}^{j}\right)^{4}$ instead of $\left(T_{2}^{j+1}\right)^{4}$.

Similarly for the penultimate node the coefficients in (1) are as follows,

$$
\left\{\begin{array}{l}
a_{I-1}^{j}=c_{I-1}^{j}=-k_{c d}\left(T_{I-1}^{j}\right) \cdot \frac{S_{c d}}{\Delta x_{c d}} \\
b_{I-1}^{j}=\rho_{c d} \cdot S_{c d} \cdot C p_{c d} \cdot \frac{\Delta x_{c d}}{2 \cdot \Delta t}+2 \cdot k_{c d}\left(T_{I-1}^{j}\right) \cdot \frac{S_{c d}}{\Delta x_{c d}}+h_{c d}\left(T_{I-1}^{j}\right) \cdot P_{c d} \cdot \frac{\Delta x_{c d}}{2} \\
d_{I-1}^{j}=\rho_{c d} \cdot S_{c d} \cdot C p_{c d} \cdot \frac{\Delta x_{c d}}{2 \cdot \Delta t} \cdot T_{I-1}^{j}+I_{e}^{2} \cdot \frac{\rho_{e, c d}\left(T_{I-1}\right)}{S_{c d}} \cdot \frac{\Delta x_{c d}}{2}+ \\
\quad+h_{c d}\left(T_{I-1}^{j}\right) \cdot P_{c d} \cdot T_{a i r} \cdot \frac{\Delta x_{c d}}{2}-\varepsilon_{c d} \cdot \sigma \cdot P_{c d} \cdot\left[\left(T_{I-1}^{j}\right)^{4}-T_{a i r}{ }^{4}\right] \cdot \frac{\Delta x_{c d}}{2}
\end{array}\right.
$$

\subsubsection{General conductor node}

The $i$-th conductor node is placed between two regular conductor nodes, that is $i-1$ and $i+1$. Fig. 5 shows the energy rate balance in this node, resulting in (25), 


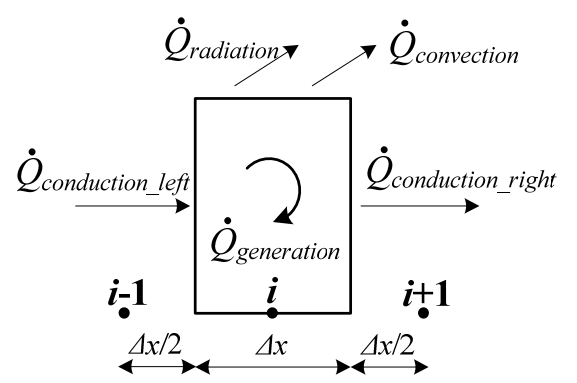

Fig. 5. Energy rate balance in a general $i$-th node of the connector.

$$
\left\{\begin{array}{l}
\dot{Q}_{\text {change }}=\rho_{c d} \cdot S_{c d} \cdot C p_{c d} \cdot \frac{T_{i}^{j+1}-T_{i}^{j}}{\Delta t} \cdot \Delta x_{c d} \\
\dot{Q}_{\text {generation }}=I_{e}^{2} \cdot \frac{\rho_{e, c d}\left(T_{i}^{j}\right)}{S_{c d}} \cdot \Delta x_{c d} \\
\dot{Q}_{\text {conduction_left }}=-k_{c d}\left(T_{i}{ }^{j}\right) \cdot \frac{T_{i}^{j+1}-T_{i-1}^{j+1}}{\Delta x_{c d}} \cdot S_{c d} \\
\dot{Q}_{\text {convection }}=h_{c d}\left(T_{i}^{j}\right) \cdot P_{c d} \cdot\left(T_{i}^{j+1}-T_{\text {air }}\right) \cdot \Delta x_{c d} \\
\dot{Q}_{\text {radiations }}=\varepsilon_{c d} \cdot \sigma \cdot P_{c d} \cdot\left[\left(T_{i}^{j}\right)^{4}-T_{a i r}{ }^{4}\right] \cdot \Delta x_{c d} \\
\dot{Q}_{\text {conduction_right }}=-k_{c d}\left(T_{i}{ }^{j}\right) \cdot \frac{T_{i+1}^{j+1}-T_{i}{ }^{j+1}}{\Delta x_{c d}} \cdot S_{c d}
\end{array}\right.
$$

Coefficients $a_{i}^{j}, b_{i}^{j}$ and $c_{i}^{j}$ in (1) are calculated by grouping terms $T_{i-1}^{j+1}, T_{i}^{j+1}$ and $T_{i+1}^{j+1}$, respectively, whereas coefficient $d^{j}$ includes the remaining terms,

$$
\left\{\begin{aligned}
a_{i}^{j}=c_{i}^{j}=-k_{c d}\left(T_{i}^{j}\right) \cdot \frac{S_{c d}}{\Delta x_{c d}} \\
b_{i}^{j}=\rho_{c d} \cdot S_{c d} \cdot C p_{c d} \cdot \frac{\Delta x_{c d}}{\Delta t}+2 \cdot k_{c d}\left(T_{i}^{j}\right) \cdot \frac{S_{c d}}{\Delta x_{c d}}+h_{c d}\left(T_{i}^{j}\right) \cdot P_{c d} \cdot \Delta x_{c d} \\
d_{i}^{j}=\rho_{c d} \cdot S_{c d} \cdot C p_{c d} \cdot \frac{\Delta x_{c d}}{\Delta t} \cdot T_{i}^{j}+I_{e}^{2} \cdot \frac{\rho_{e, c d}\left(T_{i}{ }^{j}\right)}{S_{c d}} \cdot \Delta x_{c d}+ \\
\quad+h_{c d}\left(T_{i}^{j}\right) \cdot P_{c d} \cdot T_{a i r} \cdot \Delta x_{c d}-\varepsilon_{c d} \cdot \sigma \cdot P_{c d} \cdot\left[\left(T_{i}^{j}\right)^{4}-T_{a i r}{ }^{4}\right] \cdot \Delta x_{c d}
\end{aligned}\right.
$$

\subsubsection{Intermediate conductor-connector and connector-conductor contact nodes}

These nodes are in the boundary between conductor-connector and connector-connector. As shown in Fig. 6 , they are hybrid nodes, half of the node belonging to the connector and the other half to the conductor.

Fig. 6 shows the energy rate balance in this node, resulting in (27),
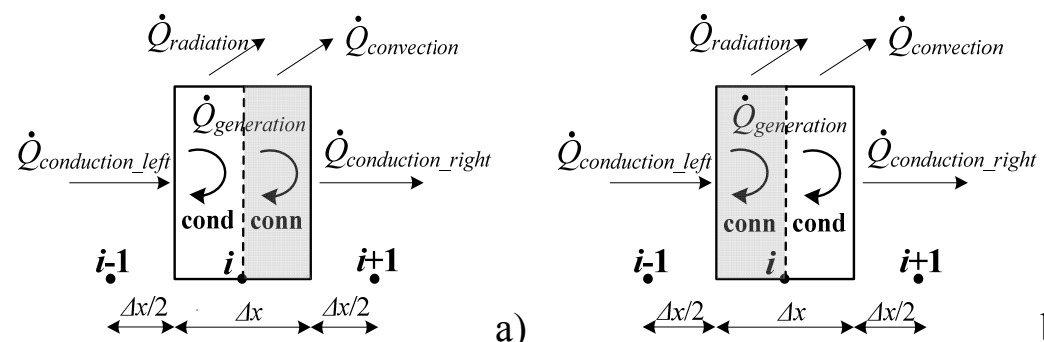

a)

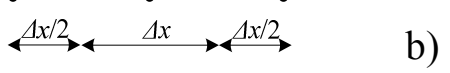

Fig. 6. Energy rate balance in the intermediate conductor-connector and connector-conductor contact nodes. 


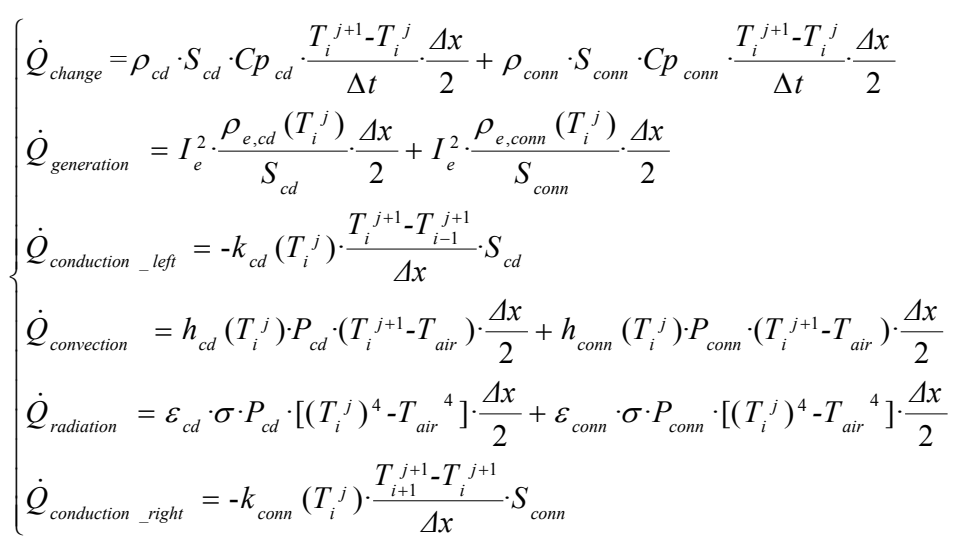

From (27), the constant coefficients in (1) for the conductor-connector contact node result in,

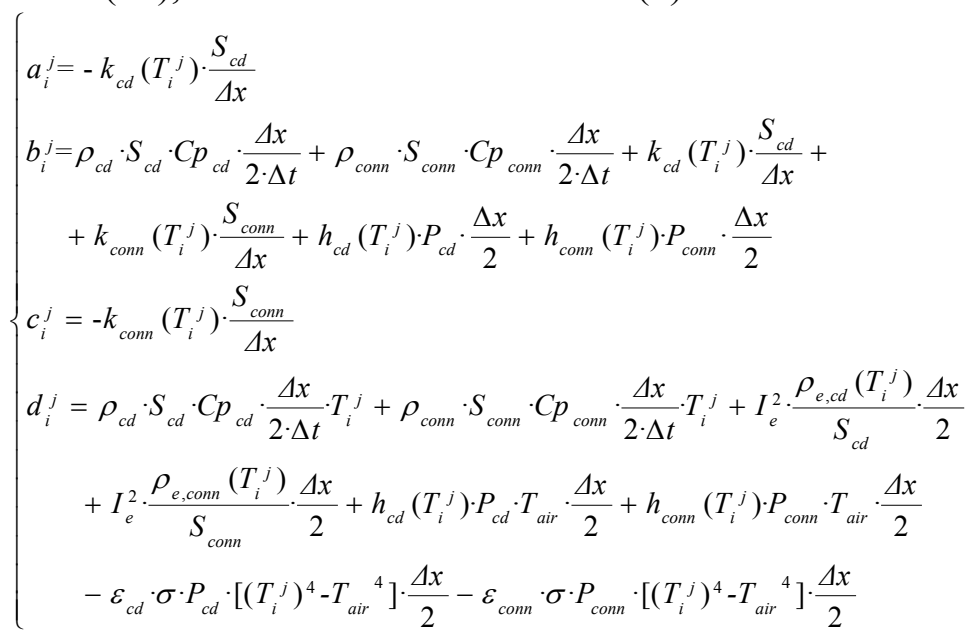

Similarly, the constant coefficients in (1) for the connector-conductor contact are the same as in (28) except,

$\left\{\begin{array}{l}a_{i}^{j}=-k_{\text {conn }}\left(T_{i}^{j}\right) \cdot \frac{S_{c o n n}}{\Delta x} \\ c_{i}^{j}=-k_{c d}\left(T_{i}^{j}\right) \cdot \frac{S_{c d}}{\Delta x}\end{array}\right.$

\subsubsection{General connector node}

The formulation and equations resulting in this node are identical to the general conductor node, but all properties must be taken from the connector material. As a consequence (23) and (24) are valid for the connector general nodes by replacing subscripts $c d$ by conn.

\subsection{Summary of the steps applied}

Fig. 7 summarizes the different steps in the proposed transient calculation method. 


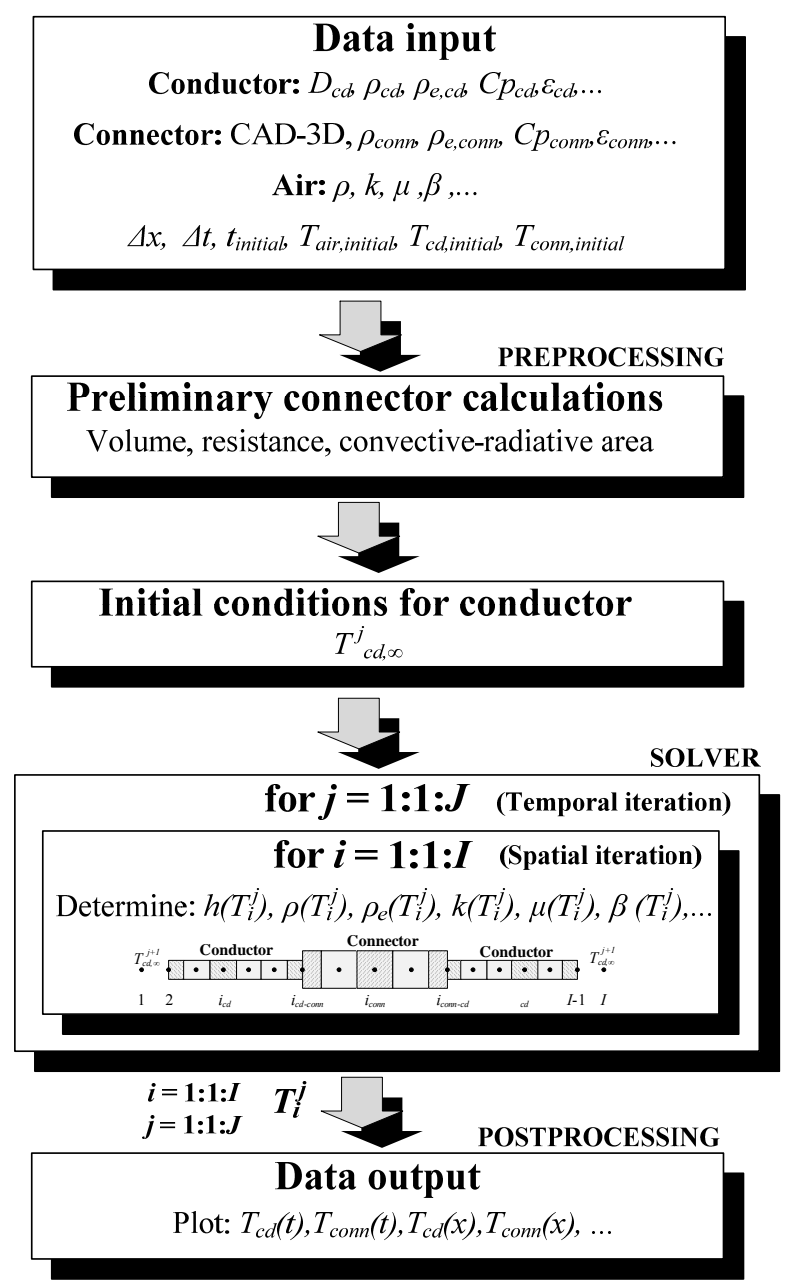

Fig. 7. Methodology summary.

Since the convective and radiative thermal processes take place in the boundary of the domain, they are evaluated taking into account the three-dimensional shapes of both the conductor and connector. The connector' and conductor' parameters providing information about their 3D shape are $S_{\text {slice, }, \text { in (13) and }}$ $S_{c o n n}, S_{c d}, h_{c o n n}, h_{c d}, P_{c o n n}$ and $P_{c d}$ in (22)-(29).

\section{Model Validation. Simulation Results Against Experimental Data}

Experimental temperature rise tests according to the ANSI/NEMA CC1-2009 standard [18] were conducted in the AMBER laboratory of the Universitat Politècnica de Catalunya to validate the simulation method proposed in this work. The test loop was composed of HTLS GTACSR-464 conductors with outer diameter $D_{c d}=20.5 \mathrm{~mm}$ and two S28ZTLS T-type connectors and four S285ZA4P23LS terminal connectors from SBI-Connectors catalogue, as shown in Fig. 8.

ANSI/NEMA CC1-2009 is the main international standard used by the substation connectors industry. This standard specifies the type of normalized tests to be applied in substation connectors, which include the temperature rise test, which evaluates the performance of the connector at $100 \%, 125 \%$ and $150 \%$ of the nominal current of the conductor at which the connector is joined. To pass the test, the temperature of the connector must always be below that of the conductor at any current level. The simulation model proposed in this paper is intended to shorten the development time of new lines of connectors and also to avoid the testing of non-compliant prototypes.

Experimental tests were performed at atmospheric conditions $\left(14.5^{\circ} \mathrm{C}, 982.7 \mathrm{hPa}\right.$ and $52.3 \%$ relative humidity) under a constant current $I_{e}=1206$ ARMs. The experimental setup includes a $120 \mathrm{kVA}$ bi-phase 
variable autotransformer [0V-400V] connected to a $120 \mathrm{kVA} 400 / 10 \mathrm{~V}$ transformer whose rated output values are $0-10 \mathrm{~V}, 0-10 \mathrm{kA}$. The output of this transformer was connected to the test loop. The loop current was measured with a calibrated Fluke i6000s-Flex Rogowski coil that has an uncertainty of $2 \%$.

Temperature measurements were performed with $16 \mathrm{~K}$-type thermocouples with a stainless steel sheath (AISI 316, $1 \mathrm{~mm}$ diameter) placed on the surface of the conductors' and connectors' bodies. The tolerance of these thermocouples is typically $2.2^{\circ} \mathrm{C}$ within the $0-275^{\circ} \mathrm{C}$ temperature interval once the temperature reading is stabilized. A small hole was drilled in the connector body to place the thermocouple, which was attached with thermal grease. Thermocouples signals were acquired every 10 seconds by means of a Tecnocat acquisition card.

Tables II and III summarize the values of the physical properties considered in the simulations.
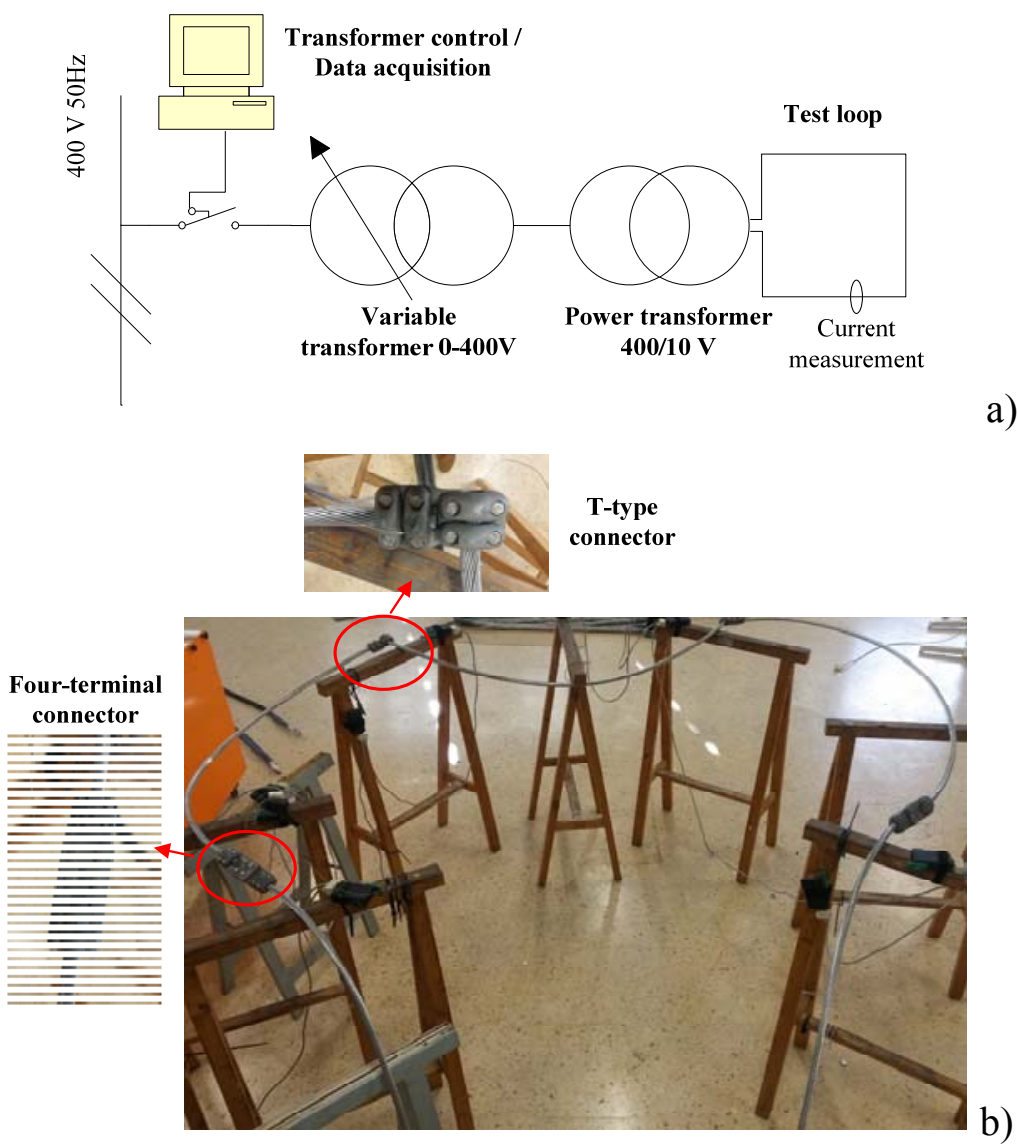

Fig. 8. Experimental setup. a) Schematics of the experimental setup. b) Test loop composed of an ACSS conductor, S285ZTLS T-connectors and S285ZA4P23LS terminal connectors.

TABLE II

PHYSICAL PROPERTIES OF THE CONDUCTOR

\begin{tabular}{ll}
\hline \hline Variable & Value \\
\hline Conductor type & GTACSR-464 \\
Aluminum conductor mass & $559.8 \mathrm{~kg} / \mathrm{km}$ \\
Steel conductor mass & $367 \mathrm{~kg} / \mathrm{km}$ \\
Diameter of the conductor & $20.47 \mathrm{~mm}$ \\
Diameter of steel core & $8.77 \mathrm{~mm}$ \\
Aluminum thermal heat capacity, $C p_{A l}$ & $534.6 \mathrm{~J} /(\mathrm{m} \cdot \mathrm{K})$ \\
Steel thermal heat capacity, $C p_{s t e e l}$ & $174.7 \mathrm{~J} /(\mathrm{m} \cdot \mathrm{K})$ \\
Conductor electrical resistivity, $\rho_{e, 20^{\circ} C}$ & $4.46 \cdot 10^{-8} \Omega \cdot \mathrm{m}$ \\
Temperature coefficient, $\alpha_{c d}$ & $0.00411 / \mathrm{K}$ \\
Aluminum thermal conductivity, $k p_{A l}$ & $229 \mathrm{~W} /(\mathrm{m} \cdot \mathrm{K})$ \\
Steel thermal conductivity, $k p_{s t e e l}$ & $43 \mathrm{~W} /(\mathrm{m} \cdot \mathrm{K})$ \\
\hline \hline
\end{tabular}


TABLE III

PHYSICAL PROPERTIES OF THE CONNECTOR

\begin{tabular}{ll}
\hline \hline Variable & Value \\
\hline Aluminum alloy & A356.0 \\
Aluminum mass density & $2700 \mathrm{~kg} / \mathrm{m}^{3}$ \\
Aluminum thermal heat capacity, $C p_{A l}$ & $534.6 \mathrm{~J} /(\mathrm{m} \cdot \mathrm{K})$ \\
Aluminum thermal conductivity, $k p_{A l}$ & $229 \mathrm{~W} /(\mathrm{m} \cdot \mathrm{K})$ \\
Connector thermal emissivity, $\varepsilon$ & 0.45 \\
Connector electrical resistivity, $\rho_{e}$ & $4.5 \cdot 10^{-8} \Omega \cdot \mathrm{m}$ \\
Temperature coefficient, $\alpha_{c d}$ & $0.0041 / \mathrm{K}$ \\
Contact resistance factor* & 2 \\
\hline \hline
\end{tabular}

* Based on measurements, it is known that the contact resistance is 2

times higher than the theoretical connector resistance

Table IV shows the time- and spatial-steps considered in the simulations performed as well as the duration of the simulations. A time step of $50 \mathrm{~s}$ and a spatial step of $0.1 \mathrm{~mm}$ were selected after carrying out a study of their values to fulfill both speed and accuracy criteria.

TABLE IV

CALCULATION PARAMETERS OF THE SIMULATION

\begin{tabular}{ll}
\hline \hline Variable & Value \\
\hline Time step $(\Delta t)$ & $50 \mathrm{~s}$ \\
Simulation time & $9000 \mathrm{~s}$ \\
Spatial step $\left(\Delta x_{c d}=\Delta x_{\text {conn }}\right)$ & $0.1 \mathrm{~mm}$ \\
\hline \hline
\end{tabular}

Figs. 9 compare the temperature evolution in the T-type connector and the conductor. Fig. 9a clearly shows that the temperature of the connector is always below than that of the reference conductor, as required by the ANSI/NEMA CC1-2009 standard. Fig. 9b displays the temperature profile along the whole geometry. It shows that the connector tends to cool the conductor portion closest to the connector, this effect being negligible at about $2 \mathrm{~m}$ far from the connector.

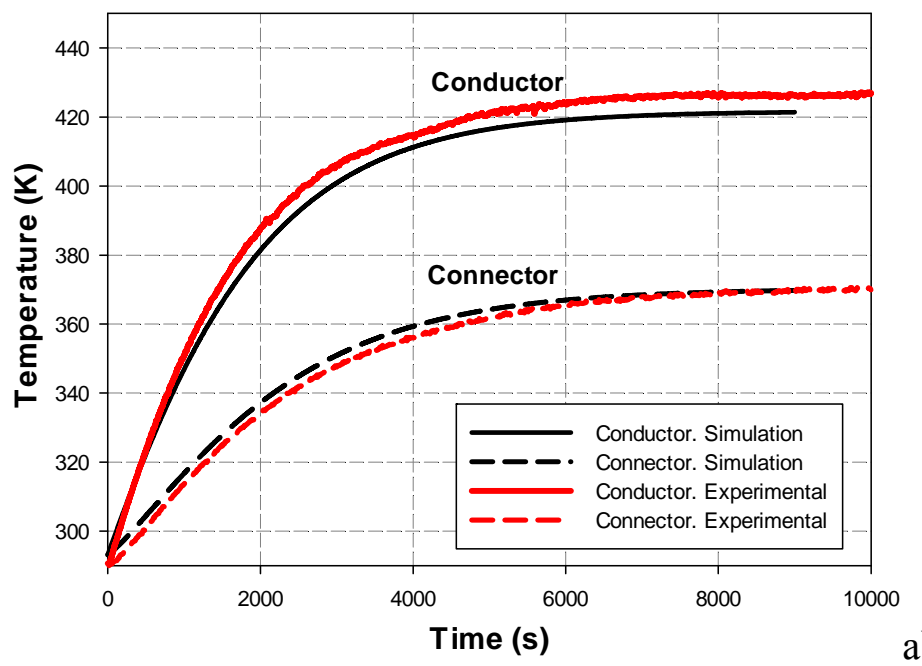

a) 

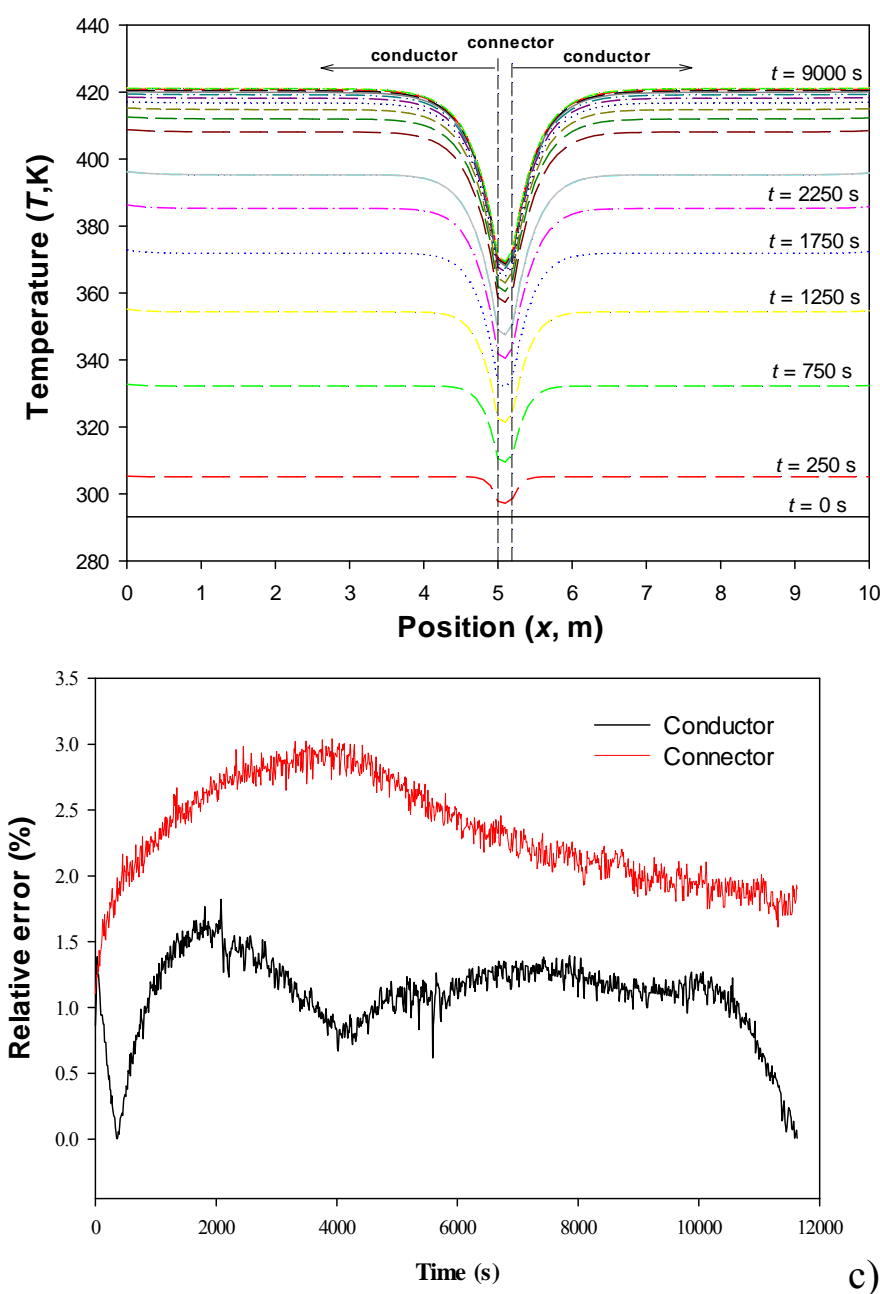

b)

Fig. 9. a) Experimental data and FDM-based simulation results of the temperature rise for both the conductor $\left(T_{c d, \infty}\right)$ and the T-type S285ZTLS connector (center point). b) Simulated temperature profile evolution with time. c) Temperature difference evolution between experimental and simulated data for the S285ZTLS connector and its reference conductor. The average relative temperature difference is $2.33 \%$ for the connector and $1.09 \%$ for the conductor.

Figs. 10 compare the temperature evolution in the terminal connector and the conductor. Once again Fig. $10 \mathrm{a}$ shows that the connector is always cooler than the reference conductor. Fig. 10b displays the temporal evolution of the temperature profile along the whole geometry.

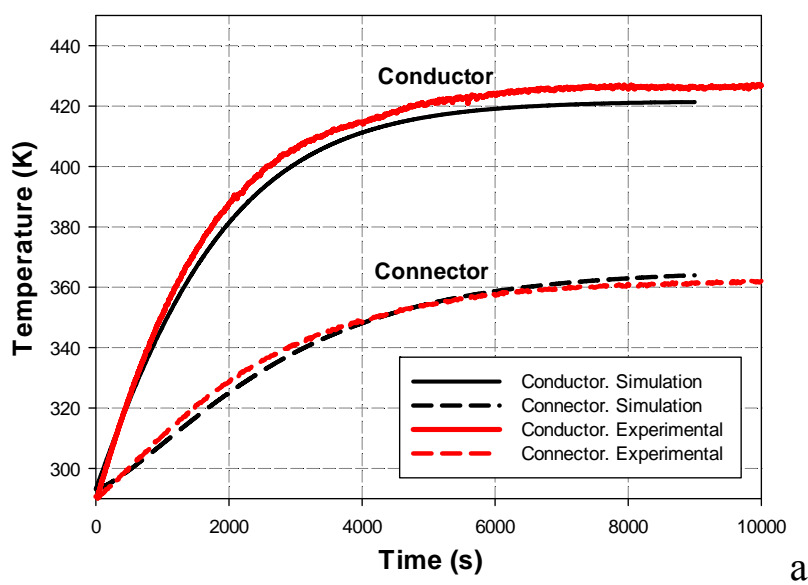




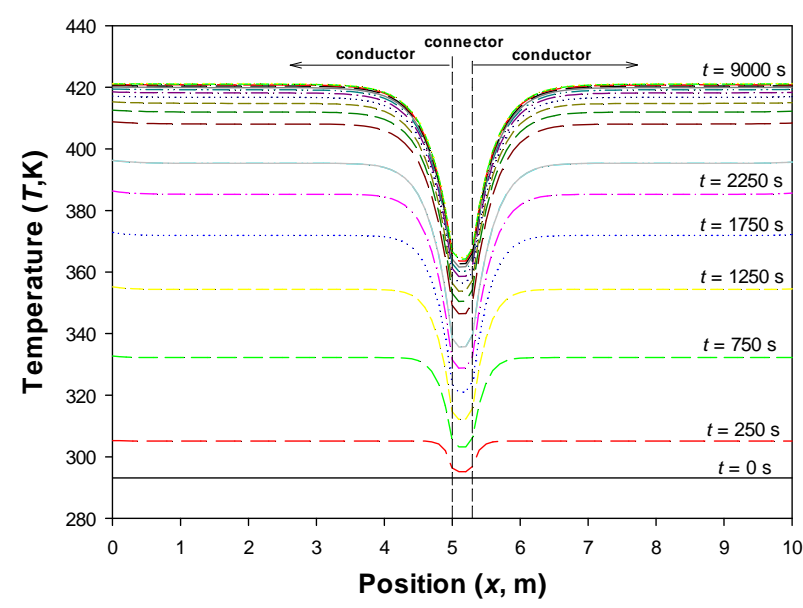

b)

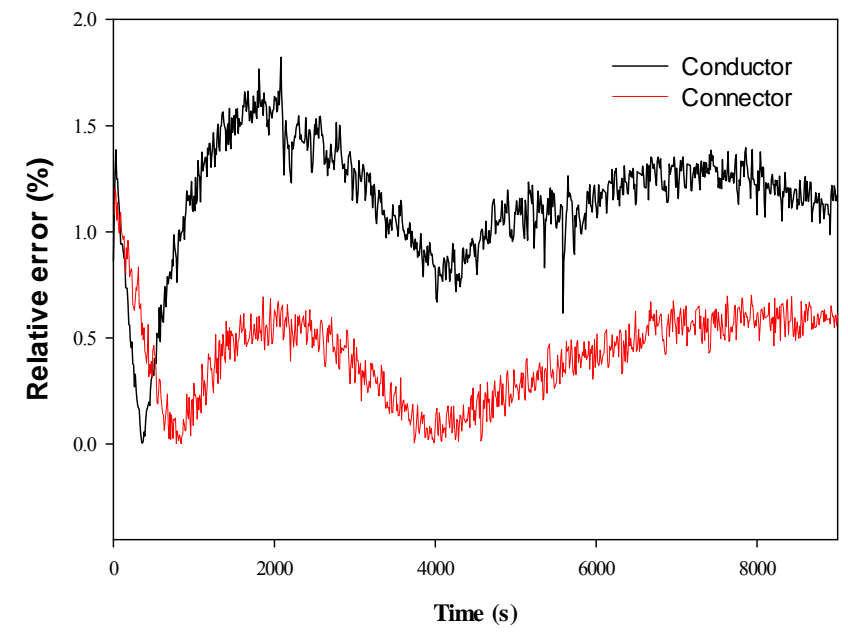

c)

Fig. 10 a) Experimental data and FDM-based simulation results of the temperature rise for both the conductor $\left(T_{c d, \infty}\right)$ and the S285ZA4P23LS terminal connector (center point). b) Simulated temperature profile evolution with time. c) Temperature difference evolution between experimental and simulated data for the S285A4P23LS connector and its reference conductor. The average relative temperature difference is $0.42 \%$ for the connector and $1.15 \%$ for the conductor.

Figs. 9a and 10a show the close agreement between experimental data and simulated temperature profiles for the conductor and the two types of analyzed connectors.

To further validate the usefulness and accuracy of the method proposed in this paper, it is validated against the experimental and 3D-FEM results presented in [27] as shown in Fig. 11. These results show comparable accuracy of the FDM-based simulation method proposed in this paper when compared with the 3D-FEM approach. 


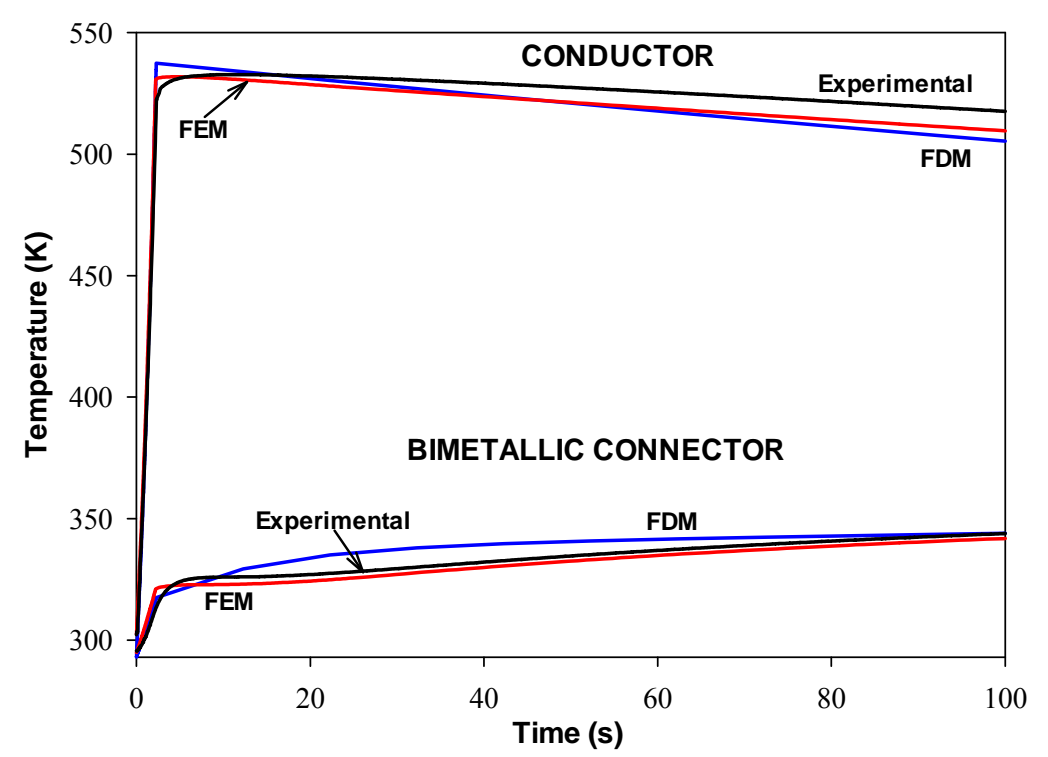

Fig. 11. Loop composed of a YAT450am20C connector and AA-1080 conductors [27]. FDM, 3D-FEM and experimental results comparison.

It is noted that the elapsed time required to run a complete simulation is about $40 \mathrm{~s}$ using an Intel-Core ${ }^{\circledR} \mathrm{i}$ $3770 \mathrm{CPU} 3.4 \mathrm{GHz}$ with $6 \mathrm{~GB}$ RAM using a code programmed in the Matlab ${ }^{\circledR} \mathrm{R} 2014 \mathrm{a}$ environment. It is much shorter than the average time required by an experienced designer to prepare the 3D-geometry, the 3D-mesh, to define the equations and boundary conditions and to run an equivalent transient 3D-FEM electromagnetic-thermal simulation.

\section{CONCLUSION}

The finite element method is a widely-used tool to design electrical devices from both electromagnetic and thermal points of view. Due to the complex three-dimensional shape of substation connectors, threedimensional FEM simulations are required which regardless of significant improvements in computer performance, are still very computationally-intensive and time-consuming, thus being expensive and sometimes unpractical when iterative simulations are required, especially during optimal design processes. To minimize these drawbacks, this paper has presented a fast and accurate FDM approach based on onedimensional reduction to simulate the temperature rise in substation connectors. The proposed transient method discretizes the original three-dimensional geometry into small one-dimensional elements in which the energy rate balance equation is applied. To improve the accuracy, the proposed one-dimensional method retains three-dimensional information of the original geometry to calculate at each time step for all analyzed surface points different parameters such as the convective coefficient of each element or the incremental resistance. It has been proved that accuracy is comparable to that attained with the 3D-FEM approach but with much less computational requirements and time involved in preparing the 3D geometries, generating the 3D mesh, or settling the boundary conditions. Experimental results conducted in a laboratory have validated the accuracy of the proposed method and its effectiveness to assist the design process of substation connectors and other power devices and components.

\section{ACKNOWLEDGEMENTS}

The authors would like to thank SBI-Connectors Spain that supported this study by provisioning the samples and the equipment required for the experimental tests. They also thank the Spanish Ministry of Economy and Competitiveness for the financial support received under contract RTC-2014-2862-3. 


\section{REFERENCES}

[1] G. Buonanno, Effect of radiative and convective heat transfer on thermal transients in power cables, IEE Proc. - Gener. Transm. Distrib. 142 (1995) 436. doi:10.1049/ip-gtd:19951956.

[2] J. Hernández-Guiteras, J.-R. Riba, L. Romeral, Improved design of an extra-high-voltage expansion substation connector through magnetic field analysis, Simul. Model. Pract. Theory. 43 (2014) 96105. doi:10.1016/j.simpat.2014.02.001.

[3] K. Hameyer, J. Driesen, H. De Gersem, R. Belmans, The classification of coupled field problems, IEEE Trans. Magn. 35 (1999) 1618-1621. doi:10.1109/20.767304.

[4] Jeong-Hoon Yoon, Heui-Sub Ahn, Jongung Choi, Il-Sung Oh, An Estimation Technology of Temperature Rise in GIS Bus Bar using Three-Dimensional Coupled-Field Multiphysics, in: Conf. Rec. 2008 IEEE Int. Symp. Electr. Insul., IEEE, 2008: pp. 432-436. doi:10.1109/ELINSL.2008.4570366.

[5] X. Li, J. Qu, Q. Wang, H. Zhao, D. Chen, Numerical and Experimental Study of the Short-Time Withstand Current Capability for Air Circuit Breaker, IEEE Trans. Power Deliv. 28 (2013) 2610 2615. doi:10.1109/TPWRD.2013.2265328.

[6] Jianyu Qu, Qian Wang, Junmin Zhang, Hu Zhao, Gang Wu, Xingwen Li, 3-D Transient FiniteElement Analysis and Experimental Investigation of Short-Circuit Dynamic Stability for Air Circuit Breaker, IEEE Trans. Components, Packag. Manuf. Technol. 5 (2015) 1610-1617.

http://ieeexplore.ieee.org/lpdocs/epic03/wrapper.htm?arnumber=7283556 (accessed February 17, 2016).

[7] X. Guan, N. Shu, B. Kang, M. Zou, Multiphysics Analysis of Plug-In Connector Under Steady and Short Circuit Conditions, IEEE Trans. Components, Packag. Manuf. Technol. 5 (2015) 320-327. doi:10.1109/TCPMT.2015.2396197.

[8] A. Mauri, R. Sacco, M. Verri, Electro-thermo-chemical computational models for 3D heterogeneous semiconductor device simulation, Appl. Math. Model. 39 (2015) 4057-4074. doi:10.1016/j.apm.2014.12.008.

[9] R. Naar, F. Bay, Numerical optimisation for induction heat treatment processes, Appl. Math. Model. 37 (2013) 2074-2085. doi:10.1016/j.apm.2012.04.058.

[10] C. Geuzaine, N. Marsic, Efficient finite element assembly of high order Whitney forms, IET Sci. Meas. Technol. 9 (2015) 204-210. https://vpn.upc.edu:11001/articleDetails.jsp?arnumber=7060808 (accessed February 14, 2016).

[11] Y. Sato, H. Igarashi, Model Reduction of Three-Dimensional Eddy Current Problems Based on the Method of Snapshots, IEEE Trans. Magn. 49 (2013) 1697-1700. https://vpn.upc.edu:11001/articleDetails.jsp?arnumber=6514733 (accessed February 14, 2016).

[12] K. Rezk, J. Forsberg, A fast running numerical model based on the implementation of volume forces for prediction of pressure drop in a fin tube heat exchanger, Appl. Math. Model. 38 (2014) 58225835. http://www.sciencedirect.com/science/article/pii/S0307904X14002315 (accessed March 16, 2016).

[13] X. Wang, Y. Jiang, Model reduction of discrete-time bilinear systems by a Laguerre expansion technique, Appl. Math. Model. (2016).

http://www.sciencedirect.com/science/article/pii/S0307904X16300798 (accessed March 19, 2016).

[14] J. Galindo, A. Tiseira, P. Fajardo, R. Navarro, Coupling methodology of 1D finite difference and 3D finite volume CFD codes based on the Method of Characteristics, Math. Comput. Model. 54 (2011) 1738-1746. doi:10.1016/j.mcm.2010.11.078. 
[15] F. Boukazouha, G. Poulin-Vittrant, L.P. Tran-Huu-Hue, M. Bavencoffe, F. Boubenider, M. Rguiti, et al., A comparison of 1D analytical model and 3D Finite Element Analysis with experiments for a Rosen-type piezoelectric transformer, Ultrasonics. 60 (2015) 41-50. doi:10.1016/j.ultras.2015.02.008.

[16] J.R. Serrano, F.J. Arnau, P. Piqueras, A. Onorati, G. Montenegro, 1D gas dynamic modelling of mass conservation in engine duct systems with thermal contact discontinuities, Math. Comput. Model. 49 (2009) 1078-1088. doi:10.1016/j.mcm.2008.03.015.

[17] B. Cerfontaine, G. Radioti, F. Collin, R. Charlier, Formulation of a 1D finite element of heat exchanger for accurate modelling of the grouting behaviour: Application to cyclic thermal loading, Renew. Energy. 96 (2016) 65-79. doi:10.1016/j.renene.2016.04.034.

[18] ANSI/NEMA, ANSI/NEMA CC1. Electric Power Connection for Substation., (2009).

[19] A.A.P. da Silva, J.M. de Barros Bezerra, A Model for Uprating Transmission Lines by Using HTLS Conductors, Power Deliv. IEEE Trans. 26 (2011) 2180-2188. doi:10.1109/TPWRD.2011.2151887.

[20] H. Cotal, J. Frost, Heat transfer modeling of concentrator multijunction solar cell assemblies using finite difference techniques, in: 2010 35th IEEE Photovolt. Spec. Conf., IEEE, 2010: pp. 000213000218. https://vpn.upc.edu:11001/articleDetails.jsp?arnumber=5614514 (accessed December 8, 2015).

[21] G.R. Kefayati, Simulation of heat transfer and entropy generation of MHD natural convection of non-Newtonian nanofluid in an enclosure, Int. J. Heat Mass Transf. 92 (2016) 1066-1089. http://www.sciencedirect.com/science/article/pii/S0017931015306256 (accessed December 3, 2015).

[22] G.R. Kefayati, FDLBM simulation of entropy generation due to natural convection in an enclosure filled with non-Newtonian nanofluid, Powder Technol. 273 (2015) 176-190.

http://www.sciencedirect.com/science/article/pii/S0032591014010249 (accessed February 22, 2016).

[23] J. Sui, N. Sugita, M. Mitsuishi, Thermal Modeling of Temperature Rise for Bone Drilling With Experimental Validation, J. Manuf. Sci. Eng. 137 (2015) 061008.

http://manufacturingscience. asmedigitalcollection.asme.org/article.aspx?articleid=2469631 (accessed February 22, 2016).

[24] C. Islam, I. Lazoglu, Y. Altintas, A Three-Dimensional Transient Thermal Model for Machining, J. Manuf. Sci. Eng. 138 (2015) 021003.

https://vpn.upc.edu/,DanaInfo=manufacturingscience.asmedigitalcollection.asme.org+article.aspx?ar ticleid $=2442369 \&$ resultClick $=3$ (accessed February 22, 2016).

[25] S.-C. Chung, B.-K. Min, Thermal Analysis of Ballscrew Systems by Explicit Finite Difference Method, Trans. KSME, A. 41 (2016) 41-51.

[26] S.A. Mohamed, R.A. Shanab, L.F. Seddek, Vibration analysis of Euler-Bernoulli nanobeams embedded in an elastic medium by a sixth-order compact finite difference method, Appl. Math. Model. 40 (2016) 2396-2406. doi:10.1016/j.apm.2015.08.019.

[27] F. Capelli, J.-R. Riba, J. Pérez, Three-Dimensional Finite-Element Analysis of the Short-Time and Peak Withstand Current Tests in Substation Connectors, Energies. 9 (2016) 418. doi:10.3390/en9060418.

[28] B.N. Datta, Numerical Linear Algebra and Applications, Second Edition, Second edi, SIAM, Philadelphia, PA, 2010. https://books.google.com/books?id=-tW8-FUoxWwC\&pgis=1 (accessed February 13, 2016).

[29] F.E. Cellier, E. Kofman, Continuous System Simulation, Springer, Riobamba, Argentina, 2006. http://www.springer.com/la/book/9780387261027 (accessed February 25, 2016). 
[30] Z.H. Qureshi, R. Ahmad, Natural convection from a uniform heat flux horizontal cylinder at moderate rayleigh numbers, Numer. Heat Transf. 11 (1987) 199-212. doi:10.1080/10407788708913550.

[31] A. Amézquita, L. Wang, C. Weller, Finite Element Modeling and Experimental Validation of Cooling Rates of Large Ready-to-Eat Meat Products in Small Meat-Processing Facilities, Biol. Syst. Eng. Pap. Publ. (2005). http://digitalcommons.unl.edu/biosysengfacpub/97 (accessed June 20, 2016).

[32] Chia-Lung Chang, Yow-Yi Hsieh, Thermal analysis of QFN packages using finite element method, in: 5th Int. Conf. Therm. Mech. Simul. Exp. Microelectron. Microsystems, 2004. EuroSimE 2004. Proc., IEEE, 2004: pp. 499-503. doi:10.1109/ESIME.2004.1304083.

[33] IEEE Power Engineering Society, IEEE Std 738-2012. IEEE Standard for Calculating the CurrentTemperature Relationship of Bare Overhead Conductors, IEEE Std 738-2012 (Revision IEEE Std 738-2006 - Inc. IEEE Std 738-2012 Cor 1-2013). (2013) 1-72.

[34] S. Boetcher, Natural Convection from Circular Cylinders, Springer, 2014. https://books.google.com/books?id=ktY7BAAAQBAJ\&pgis=1 (accessed February 12, 2016).

[35] Z.H. Qureshi, R. Ahmad, Natural convection from a uniform heat flux horizontal cylinder at moderate rayleigh numbers, Numer. Heat Transf. 11 (1987) 199-212. http://www.tandfonline.com/doi/abs/10.1080/10407788708913550 (accessed February 19, 2016).

[36] E.R.G. Eckert, R.M. Drake, Analysis Of Heat And Mass Transfer, Springer-Verlag, Berlin, Germany, 1972. 